\title{
Incidence of respiratory syncytial virus infection in children with congenital heart disease undergoing immunoprophylaxis with palivizumab in Pará state, north region of Brazil
}

Roseane Porfírio de Souza ${ }^{1,2}$, Andre Luis Ribeiro Ribeiro ${ }^{3}$, Sílvio Augusto Fernandes de Menezes ${ }^{4}$ and Luiz Fernando Almeida Machado ${ }^{1,5^{*}}$

\begin{abstract}
Background: Palivizumab prophylaxis for the human respiratory syncytial virus (HRSV) has been reported to reduce the risk of hospital admissions related to HRSV in children with congenital heart disease (CHD). These children are at high risk of developing severe lower respiratory tract infection (LRTI) due to HRSV infection. Our goal was to evaluate the incidence of HRSV infection in children with CHD after being submitted to immunoprophylaxis with palivizumab in Pará state, North region of Brazil.

Methods: A prospective and observational cohort study was performed in children $\leq 2$ years of age with CHD who received palivizumab immunoprophylaxis between January 1 and June 31, 2016. A questionnaire about basic nonmedical care measures was applied to parents/legal representatives. Data on patients' demographic characteristics, household environment, and respiratory infections were evaluated. HRSV infection was determined by qPCR.

Results: There were 104 children enrolled in this investigation and the results showed a mean age of 10.6 months, an average weight of $7.3 \mathrm{~kg}$ and 3.5 doses of palivizumab per children during seasonality of HRSV. Respiratory infection was observed in $27.9 \%$ of cases, of which $9.6 \%$ were LRTI. No case of children who received palivizumab immunoprophylaxis and developed influenza-like symptoms tested positive for HRSV.
\end{abstract}

Conclusion: Although the lack of a control group doesn't allow to affirm the effectiveness of HRSV passive immunization, the immunoprophylaxis with palivizumab appeared to be totally efficient in preventing respiratory infection by HRSV in children up to two years of age with CHD.

Keywords: Respiratory syncytial virus, Immunization, Palivizumab, Respiratory tract infections

\section{Background}

The human respiratory syncytial virus (HRSV) is the most common etiologic agent of acute lower respiratory tract infection (LRTI) in neonates and children under five years of age worldwide [1] and it is the fourth cause of death in this

\footnotetext{
* Correspondence: Ifam@ufpa.br

${ }^{1}$ Biology of Infectious and Parasitic Agents Post-Graduate Program, Federal University of Pará, Belém, Pará, Brazil

${ }^{5}$ Virology Laboratory, Institute of Biological Sciences, Federal University of Pará, Cidade Universitária Prof. José da Silveira Netto, Rua Augusto Correa 1 , Guamá, 66.075-110, Belém, Pará, Brazil

Full list of author information is available at the end of the article
}

group of children in Brazil [2]. HRSV infection is associated with risk factors such as overpopulation, pollution and malnutrition [3]. Children with congenital heart disease (CHD) are at high risk of developing acute LRTIs, and HRSV infection increases the chances of developing more severe LRTIs and extends the length of hospitalization because of respiratory complications. It increases not only the morbidity and mortality rates of these children but also the treatment costs due to higher admission rates in intensive care units, longer oxygen therapy and mechanical ventilation among those children [4]. It is estimated that 3.4 million

(c) The Author(s). 2019 Open Access This article is distributed under the terms of the Creative Commons Attribution 4.0 International License (http://creativecommons.org/licenses/by/4.0/), which permits unrestricted use, distribution, and reproduction in any medium, provided you give appropriate credit to the original author(s) and the source, provide a link to the Creative Commons license, and indicate if changes were made. The Creative Commons Public Domain Dedication waiver (http://creativecommons.org/publicdomain/zero/1.0/) applies to the data made available in this article, unless otherwise stated. 
hospitalizations and 199,000 deaths occur globally as a result of HRSV infection [1].

HRSV infections occur predominantly in well-defined seasons, usually during autumn and winter, and in temperate and subtropical regions. These seasons last between 16 to 20 weeks annually [5, 6] and often matches with the seasonality of the influenza virus [7]. The prevalence of HRSV infection in Brazil is derived from the data of the Influenza Sentinel Surveillance Information System and other respiratory viruses (SIVEP-FLIPE). It was based on data from influenza-like reports of illness during the period of 2007 to 2014. This data showed that HRSV infection has a different seasonality depending on the region in the country [8]. Based on that, the Ministry of Health (Joint Technical Note no. 05/2015) defined the regional seasonality of HRSV infection in different regions in Brazil, which in the North region corresponds to the period from January to June [8].

Although HRSV infection activates the immune system, acquired immunity does not prevent reinfection and vaccination with attenuated viruses appears to aggravate subsequent diseases [9]. Thus, the Ministry of Health of Brazil [10] has established measures to reduce the transmission of HRSV with passive immunization using the monoclonal antibody palivizumab (Synagis, MedImmune Laboratory, Gaithersburg, USA), which is composed of $95 \%$ human and 5\% murine amino acid sequences. It was established by law and includes a population of preterm babies $(<28$ weeks) who are not older than 12 months; and children up to two years of age with either CHD with hemodynamic significance or with chronic lung disease. Administration of palivizumab is performed intramuscularly at a dose of $15 \mathrm{mg} / \mathrm{kg}$ [11].

So far, no epidemiologic survey has been performed to check the efficacy of the palivizumab program since it's beginning in Pará state. Thus, this study aimed to evaluate the incidence of HRSV in children ( $<2$ years of age) with CHD who were submitted to immunoprophylaxis with palivizumab in Belém, Pará, Brazil. This study also investigated the knowledge of children's parents/legal representatives regarding basic non-medical care measures to reduce HRSV transmission; the efficiency of the palivizumab program and its recommended monthly doses; and analysed the incidence of respiratory infections caused by HRSV in children after palivizumab immunization in a specialized reference hospital in cardiology in Belém, Brazil.

\section{Materials and methods}

\section{Study design, population studied and ethical aspects}

This was a prospective observational cohort study involving children with $\mathrm{CHD}$ who were participating of the palivizumab program attending various sectors (e.g. outpatient clinic, neonatal intensive care unit, paediatric clinic and intensive care unit and paediatrics) of the Gaspar Vianna Public Foundation Hospital (FHCGV). This is specialized and a reference hospital in cardiology located in Belém, Pará, Brazil. The FHCGV carries out the assistance program for children with cardiopathy (PAPCC), where children receive outpatient care from nurses, social workers, psychologists, nutritionists, dentists, paediatricians and paediatric cardiologists. All children with CHD enrolled in the PAPCC whose parents/ legal representatives agreed to join the study and received palivizumab immunoprophylaxis for HRSV from January to June 2016 were included in our sample.

This study was approved by the Ethics Committee of the Gaspar Vianna Public Foundation Hospital under protocol number 53017116.5.0000.0016, according to the resolution 466/2012 of the National Health Council. The parents or legal guardians of the participant children signed an informed consent form and answered questions regarding basic non-medical care measures to reduce HRSV transmission. The questionnaire included 8 qualitative yes / no questions.

\section{Inclusion and exclusion criteria}

All children younger than 2 years of age from both sexes, who had CHD with confirmed haemodynamic significance and received at least one dose of palivizumab during the study period were included. To receive palivizumab immunoprophylaxis, the child should fill the criteria established by the FHCGV outpatient clinic: 1 - to be selected according to the protocol for the palivizumab program; 2 - to be prescribed by a paediatrician or paediatric cardiologist 3- to have determined the full treatment (number, timing and concentrations of palivizumab doses); 4- received the complete guidelines of treatment; 5- to have all palivizumab doses recorded on the medical records. Children who received the treatment but failed to return for taking subsequent doses or did not show up on follow-up appointments were excluded from our samples.

\section{Sampling and follow-up}

On the day of administration of the first palivizumab dose, all children were weighted and reviewed by a paediatrician or paediatric cardiologist. Palivizumab doses were calculated and the overall clinical conditions checked before drug administration. Doses were calculated using the following formula: weight in kilos times 15 (ideal dose $/ \mathrm{kg}$ of palivizumab) divided by 100 (the concentration of palivizumab in $\mathrm{mg} / \mathrm{mL}$ in use). Hospitalized children were evaluated by the assistant paediatrician.

Palivizumab immunization was carried out in monthly doses and the total number of doses taken was based on the time of enrolment in the program. Children who were enrolled in January could take a total of 6 doses, however, those who enrolled after January were given 
the same monthly dose, which resulted in a lower number of total doses taken. Parents or legal representatives were invited to participate in this study and those who agreed to join in, signed the consent form and answered a questionnaire. An active search for clinical manifestations suggestive of HRSV infection post-immunoprophylaxis with palivizumab was carried out through phone calls monthly.

\section{Palivizumab treatment records}

A structured form was used to record the palivizumab doses taken and post-immunoprophylaxis follow-up. During the study, it was established that any child who developed influenza-like symptoms (cough or sore throat, rhinorrhoea, coryza and malaise) should come to the outpatient clinic of the FHCGV from Monday to Friday, no later than the fifth day of the beginning of symptoms. All children with influenza-like symptoms were tested according to the protocol of the Global Influenza Program [12] to investigate respiratory infection caused by HRSV, which also included those children who developed LRTI and required hospitalization. Tests for HRSV infection and other respiratory viruses were performed in the Central Public Health Laboratory of Pará (LACEN-PA).

HRSV infection was determined by quantitative polymerase chain reaction ( $\mathrm{qPCR}$ ), which is considered one of the most accurate tests for detecting HSRV strains [13]. Amplicons signals were measured relative to the internal reference dye (ROX) to normalize for non-PCRrelated fluorescence fluctuations occurring from well to well. The qPCR protocol used was standardized by the Centre for Disease Control and Prevention (CDC), Ministry of Health of Brazil and its efficiency has been largely tested across the country. Positive results were determined by the fluorescence intensity values of our samples compared to a positive control previously established by the CDC.

Data from cases that developed LRTI caused by HRSV were retrieved from medical records. Information regarding the length of stay during hospitalization, number of doses of palivizumab received, use of supplementary oxygen and mechanical ventilation, intensive care unit (ICU) admission, and death was collected. Furthermore, additional information included the seasonality of the HSRV infection, the beginning and ending of treatment, and other upper and lower respiratory tract infection. In this study, the cities of Ananindeua, Marituba, Benevides, Santa Bárbara do Pará, Santa Isabel do Pará and Castanhal were considered as the Belém metropolitan area.

\section{Data analysis}

Data were inputted on Microsoft ${ }^{\oplus}$ Access 2010 database and summarized in tables. The following variables were considered: the geographical location, other preventive
HSRV infection measures (apart from palivizumab immunoprophylaxis), children's demographic data on the day of the first dose (age, gender, weight), follow-up period, volume and number of doses of palivizumab prescribed.

\section{Results}

There were 104 children who fulfilled the inclusion criteria and received immunoprophylaxis with palivizumab from January to June 2016 at the FHCGV in Belém, Pará. One child was excluded because the treatment with palivizumab was administered for a non-cardiologic reason.

Eight questions were asked to children's parents or legal representatives about their knowledge of basic nonmedical measures to reduce the transmissibility of HRSV. Results showed that $77 \%(80 / 104)$ of the children's parents or legal representatives knew about the need of washing hands to prevent virus transmission; $70 \%$ (73/104) performed hands hygiene before and after contact with the child; and 69\% (72/104) had been advised of avoiding exposure of the child to passive smoking. Answers to all questions of the questionnaire are in Table 1.Two-thirds of these measures were known by children's parents or legal representatives and less than half of them were aware of vaccination against influenza virus as preventive care.

There were $58 \%(60 / 104)$ of males and $42 \%(44 / 104)$ of females. The geographical location indicated that $54 \%$ $(56 / 104)$ of participants came from the countryside, $29 \%$ $(30 / 104)$ lived in the city of Belém, and 17\% (18/104) were residents from the Belém metropolitan area. The FHCGV outpatient clinic was responsible for 81\% (84/ $104)$ of the source of participants, $10 \%$ (11/104) was assisted on the paediatric clinic, 6\% (6/104) came from neonatal ICU and 3\% (3/104) from other sectors of the hospital. The beginning of immunoprophylaxis with palivizumab was in January for 32\% (33/104) of the cases,

Table 1 Analysis of the knowledge of parents and legal representatives of children who received immunoprophylaxis with palivizumab at the FHCGV from January to June of 2016 on general measures of non-drug basic care to reduce the transmissibility of HRSV

\begin{tabular}{lll}
\hline Preventive HRSV infection measures & $\mathrm{n}$ & $\%$ \\
\hline Appropriated hand hygiene & 80 & 76.9 \\
Cleaning of hands before and after contact with the child & 73 & 70.2 \\
Avoid exposure of the child to passive smoking & 72 & 69.2 \\
Reinforcement of the child personal hygiene & 71 & 68.3 \\
Disinfection of contaminated surfaces & 71 & 68.3 \\
Limit contact with people with a respiratory infection & 69 & 66.4 \\
Avoid agglomerations & 67 & 64.4 \\
Vaccination against influenza virus & 49 & 47.1 \\
Total & & 66.3 \\
\hline
\end{tabular}


followed by February with 26\% (27/104) and March with 19\% (20/104).

Palivizumab immunoprophylaxis was given only during the regional epidemic season of HRSV (January to June). Children who started the immunization in January had a chance to take all the six doses; the others were given monthly doses according to the month of enrolment until June. Of all participating children, only 17 (16.3\%) had received 6 doses of palivizumab during the study and 24 (23.0\%) received two doses. Demographic data including palivizumab treatment information is shown in Table 2.

The average age during the beginning of palivizumab immunoprophylaxis was 10.6 months ( $\mathrm{SD} \pm 6.6)$, mean weight was $7.3 \mathrm{~kg}(\mathrm{SD} \pm 2.7)$, average dose of palivizumab was of $1.1 \mathrm{~mL}(\mathrm{SD} \pm 0.4)$ and the mean number of doses given during the study was $3.5(\mathrm{SD} \pm 1.7)$.

Table 2 Demographic data of children with CHD who received immunoprophylaxis with palivizumab at the FHCGV from January to June 2016, in Belém, Pará, Brazil

\begin{tabular}{|c|c|c|}
\hline Characteristics & $n$ & $\%$ \\
\hline \multicolumn{3}{|l|}{ Gender } \\
\hline Male & 60 & 57.7 \\
\hline Female & 44 & 42.3 \\
\hline \multicolumn{3}{|l|}{ Geographic origin } \\
\hline Belém & 30 & 28.8 \\
\hline Belém metropolitan area & 18 & 17.3 \\
\hline Countryside & 56 & 53.9 \\
\hline \multicolumn{3}{|l|}{ Hospital sector of origin } \\
\hline Outpatient clinics & 84 & 80.8 \\
\hline Esternal outpatient clinics & 3 & 2.9 \\
\hline Paeditrics clinics & 11 & 10.5 \\
\hline Neonate ICU & 6 & 5.8 \\
\hline \multicolumn{3}{|c|}{ Month of the beginning of immunoprophylaxis } \\
\hline January & 33 & 31.7 \\
\hline February & 27 & 26.0 \\
\hline March & 20 & 19.2 \\
\hline April & 10 & 9.6 \\
\hline May & 10 & 9.6 \\
\hline June & 4 & 3.8 \\
\hline \multicolumn{3}{|c|}{ Number of palivizumab doses taken } \\
\hline 1 dose & 16 & 15.4 \\
\hline 2 doses & 24 & 23.1 \\
\hline 3 doses & 15 & 14.4 \\
\hline 4 doses & 13 & 12.5 \\
\hline 5 doses & 19 & 18.3 \\
\hline 6 doses & 17 & 16.3 \\
\hline
\end{tabular}

Medical records showed that 28\% (29/104) of children had at least one episode of respiratory tract infection, with a ratio of 1.3 episodes of infection per patient $(\mathrm{SD} \pm$ $0.4)$. It resulted in 40 respiratory infections during the period of study.

Thirty out of 40 respiratory infections $(75 \%)$ were on the upper respiratory tract and $10(25 \%)$ involved the lower respiratory tract (Table 3). The mean length of stay in the hospital due to these infections was 51 days $(\mathrm{SD} \pm 35)$. From those children who developed LRTI, $10 \%(1 / 10)$ presented bronchiolitis, 50\% (5/10) had pneumonia, and $10 \%(1 / 10)$ developed both, bronchiolitis and pneumonia. Admission to ICU due to LRTI was required for $50 \%(5 / 10)$ of children and the average length of stay in the ICU was 24 days. From these children, $40 \%(4 / 10)$ required only oxygen therapy and 30\% $(3 / 10)$ needed mechanical ventilation (Table 4). During the LRTI, the nasopharyngeal aspirate was positive for metapneumovirus in $20 \%(2 / 10)$ of the cases. In the follow-up period, one child has passed away 0.9\% (1/104) due to a non-respiratory cause after cardiac surgery.

\section{Discussion}

To our knowledge, this is the first study in the North region of Brazil that investigated the incidence of HRSV infection after the use of palivizumab passive immunization in children with CHD. Our results showed that there was not even a single case of HRSV positive test after palivizumab immunization.

Although the incidence of HRSV in children with CHD in this region is not known, data from the influenza sentinel surveillance system (SIVEP-Gripe) indicated a prevalence of $9.6 \%$ of HSRV positivity in children younger than 5 years of age with influenza-like symptoms [14]. Other studies that focused on a population with a similar age (younger than 2 years), showed a prevalence of $52 \%$ of HRSV infection in children with acute respiratory tract infections (São Paulo, Brazil) [15] and 40.2\% in children with LRTI in the Northeast region [16]. Since 29 (27.9\%) of the participant children in this study had a respiratory infection, it was expected that at least a few children would be infected by the HSRV, the most common aetiological agent in this type of infections $[15,16]$. However, no case

Table 3 Incidence of respiratory tract infection in 104 children with congenital heart disease after immunoprophylaxis with palivizumab in Belém, Brazil from January to June 2016

\begin{tabular}{lll}
\hline Respiratory infection information & $\mathrm{n}$ & $\%$ \\
\hline Upper respiratory tract infection (URTI) & 30 & 28.8 \\
Lower respiratory tract infection (LRTI) & 10 & 9.6 \\
Diagnosis in outpatient clinic & 27 & 26.0 \\
LRTI acquired during hospitalization & 3 & 2.9 \\
Hospitalization due to respiratory infection & 7 & 6.8 \\
\hline
\end{tabular}


Table 4 Diagnostic and medical care needed for treating 10 children who developed lower respiratory tract infection (LRTI) after immunoprophylaxis with palivizumab in the Belém, Brazil from January to June 2016

\begin{tabular}{lll}
\hline LRTI information & $\mathrm{n}$ & $\%$ \\
\hline Pneumonia & 5 & 50 \\
Metapneumovirus infection & 2 & 20 \\
Bronchiolitis & 1 & 10 \\
Bronchiolitis and pneumonia & 1 & 10 \\
ICU admission & 5 & 50 \\
Oxygen therapy use & 4 & 40 \\
Mechanical ventilation use & 3 & 30 \\
\hline
\end{tabular}

of HRSV infection was identified in our sample, suggesting that palivizumab immunization was effective in preventing respiratory infections caused by HRSV.

Children started immunoprophylaxis with palivizumab with a mean age of 10.6 months, which was older than that found in São Paulo (8.4 months) [17] and in children with heart disease in Korea (2.9 months) [18]. The mean weight of the participant children during the first dose of treatment was $7.3 \mathrm{~kg}$ and resulted in an average dose of $1.1 \mathrm{~mL}$ of palivizumab $(100 \mathrm{mg} / \mathrm{mL})$, in accordance with the standards of the Brazilian Ministry of Health [10].

The average number of doses of palivizumab injections during the study period was 3.5 doses/child, similar to that reported in Korea (3.7 doses) [18], Latin America (3.8 doses) [19] and in São Paulo (4 doses) [17]. Five doses of palivizumab were given to $34.6 \%$ of children, a percentage higher than reported in São Paulo (22.7\%) [17] but lower than in Latin America (43.7\%) [19]. Since palivizumab is only administered during the HRSV epidemic season (January to June in the North region of Brazil), the reduced number of doses could be a result of the difficulties of countryside children travelling to Belém in order to take their medication. It is important to mention that the Pará state has a huge territorial extension and the transportation system is poor, making the commuting from their hometown to Belém a challenging task. Thus, only children who started immunoprophylaxis during the months of January and February had the chance of receiving 5 doses.

There were 40 respiratory infections in 29 children (28\%) with predominantly upper respiratory tract infections. Similar results were observed in Argentina (32\%) [20] and much lower than in Korean children (61\%) [18], Italy (76.4\%) [21] and São Paulo (59.1\%) [17]. We also identified an overall low incidence of LRTI (9.6\%), which is much lower than that reported in São Paulo (40.6\%) [17]. However, it may reflect differences in the studied population that did not include children with chronic lung disease in our study. Hospitalization was barely required (6.8\%), which was lower than São Paulo (9\%) [17], and even much lower than in Italy (22.9\%) [21], Argentina (31\%) [20] and Korea (60\%) [18].

All children participating in this study had taken at least 1 dose palivizumab immunoprophylaxis while free of respiratory infections. Those children who developed a respiratory infection were previously passively immunized against HRSV. Since the immunization is passive, maintenance of the regular monthly immunization is the key point for preventing HRSV infection and it is not related to the total number of doses.

Although uncommon, when hospitalization was required, patients stayed for a long period (average of 51 days). It reflects the vulnerability of this specific population that have other medical problems requiring treatment, which can be aggravated due to their susceptibility to several other viral and bacterial infections. This long hospitalization stay is a result of a combination of other associated medical problems and excessive bureaucracy and slowness of the Brazilian public health system.

The respiratory infections found in this study were classified as bronchiolitis in $10 \%$ of cases, lower than in São Paulo (50\%) [17] and Italy (22.9\%) [21]. We did not observe any case of HRSV infection, suggesting a full efficacy of palivizumab immunoprophylaxis. However, we can not affirm its effectiveness since we did not include a control group of similar patients who did not take the passive immunization with palivizumab.

\section{Conclusion}

The use of palivizumab immunoprophylaxis appeared to be effective in preventing HRSV infection, especially the LRTI in children CHD. Although respiratory infections were present in $27.9 \%$ of children enrolled in our study, none of them tested positive to HRSV, which reinforces the suggested efficacy of the palivizumab passive immunization, carried out by the Brazilian Ministry of Health for children with CHD, in preventing the incidence and complications related to respiratory infections caused by HRSV.

\section{Abbreviations \\ CHD: congenital heart disease; FHCGV: Gaspar Vianna Public Foundation Hospital; HRSV: human respiratory syncytial virus; LACEN-PA: Central Public Health Laboratory of Pará; ICU: intensive care unit; LRTI: lower respiratory tract infections; PAPCC: assistance program for children with cardiopathy; SIVEP-FLIPE: Influenza Sentinel Surveillance Information System and other respiratory viruses}

\section{Acknowledgements}

The authors thank the Secretaria de Saúde do Município de Belém - Brasil, the director board of the Centro de Atendimento em Doenças Infecciosas Adquiridas (CASA-DIA), and all participants of this study.

Authors' contributions

RPS and LFAM have contributed to the consemption and design of this study. RPS has performed data acquisition. ALRR and SAFM have analyzed and interpreted the data. RPS, LFAM and ALRR have drafted and revised the 
work. All authors have approved the submitted version, agreed to author's personal contributions and ensure the accuracy and integrity of this work.

\section{Funding}

This study was fnanced in part by the Coordenação de Aperfeiçoamento de Pessoal de Nível Superior - Brasil (CAPES) - Finance Code 001. PAPQ, PROPESP/FADESP of the Federal University of Pará, supported the publication of this article. These funding bodies have agreed to pay the article processing charges.

The author Andre Luis Ribeiro Ribeiro is grateful to the CNPq for his postdoctoral scholarship. CNPq - Brazil (nº 153811/2018-8).

The funding bodies did not have any role in designing the study; collecting, analysing, and interpretating the data; and in writing the manuscript.

\section{Availability of data and materials}

Not applicable.

\section{Ethics approval and consent to participate}

This study was approved by the Ethics Committee of the Gaspar Vianna Public Foundation Hospital under protocol number 53017116.5.0000.0016. Although no individual person detail is shown in this work, all parents or legal guardians signed a consent form

\section{Consent for publication}

Not applicable.

\section{Competing interests}

The authors declare that they have no competing interests.

\section{Author details}

${ }^{1}$ Biology of Infectious and Parasitic Agents Post-Graduate Program, Federal University of Pará, Belém, Pará, Brazil. 'aspar Vianna Clinic Hospital Foundation, Belém, Pará, Brazil. ${ }^{3}$ Postdoctoral fellowship, Cell Culture Laboratory, School of Dentistry, Federal University of Para - UFPA, Belém, Pará, Brazil. ${ }^{4}$ Clinical lecturer, Department of Periodontology, School of Dentistry, University Centre of Para - CESUPA, Belém, Pará, Brazil. ${ }^{5}$ Virology Laboratory, Institute of Biological Sciences, Federal University of Pará, Cidade Universitária Prof. José da Silveira Netto, Rua Augusto Correa 1, Guamá, 66.075-110, Belém, Pará, Brazil.

Received: 23 January 2019 Accepted: 21 August 2019

Published online: 28 August 2019

\section{References}

1. Nair H, Nokes DJ, Gessner BD, Dherani M, Madhi SA, Singleton RJ, et al. Global burden of acute lower respiratory infections due to respiratory syncytial virus in young children: a systematic review and meta-analysis. Lancet. 2010;375:1545-55.

2. Ferone EA, Berezin EN, Durigon GS, Finelli C, Fellcio MC, Storni JG, et al. Clinical and epidemiological aspects related to the detection of adenovirus or respiratory syncytial virus in infants hospitalized for acute lower respiratory tract infection. J Pediatr. 2014;90(1):42-9.

3. Law BJ, Langley JM, Allen U, Paes B, Lee DS, Mitchell I, et al. The Paediatric investigators collaborative network on infections in Canada study of predictors of hospitalization for respiratory syncytial virus infection for infants born at 33 through 35 completed weeks of gestation. Pediatr Infect Dis J. 2004;23(9):806-14.

4. MacDonald NE, Hall CB, Suffin SC, Alexson C, Harris PJ, Manning JA Respiratory syncytial viral infection in infants with congenital heart disease. N Engl J Med. 1982;307(7):397-400

5. Zachariah P, Shah S, Gao D, Simões EA. Predictors of the duration of the respiratory syncytial virus season. Pediatr Infect Dis J. 2009;28(9):772-6.

6. Schmidt R, Majer I, García Román N, Rivas Basterra A, Grubb E, Medrano López C. Palivizumab in the prevention of severe respiratory syncytial virus infection in children with congenital heart disease; a novel cost-utility modeling study reflecting evidence-based clinical pathways in Spain. Health Econ Rev. 2017:7(1):47.

7. Reis J, Shaman J. Retrospective parameter estimation and forecast of respiratory syncytial virus in the United States. PLoS Comput Biol. 2016; 12(10):e1005133.
8. Brasil. Ministério da Saúde. Nota Técnica Conjunta nº5 de 09 de fevereiro de 2015. Estabelece a Sazonalidade do Vírus Sincicial Respiratório no Brasil e Oferece Esclarecimentos Referentes ao Protocolo de Palivizumabe. Brasília: Ministério da Saúde; 2015

9. Andabaka T, Nickerson JW, Rojas-Reyes MX, Rueda JD. Bacic Vrca V, Barsic B. monoclonal antibody for reducing the risk of respiratory syncytial virus infection in children. Cochrane Database Syst Rev. 2013;30(4):CD006602.

10. da Saúde M. Portaria no 522, de 13 de maio de 2013. Aprova o protocolo de uso do palivizumabe. Diário Oficial da União. 2013;14:mai.

11. European Medicines Agency (EMA). Summary of Product Characteristics Synagis $50 \mathrm{mg}$ (palivizumab) 2009. Accessed on 01 ${ }^{\text {st }}$ May 2019 in https:// www.ema.europa.eu/en/documents/product-information/synagis-eparproduct-information_en.pdf

12. Broadbent $L$, Groves $H$, Shields MD, Power UF. Respiratory syncytial virus, an ongoing medical dilemma: an expert commentary on respiratory syncytial virus prophylactic and therapeutic pharmaceuticals currently in clinical trials. Influenza Other Respir Viruses. 2015:9(4):169-78.

13. van Elden LR, van Loon AM, van der Beek A, Hendriksen KAW, Hoepelman AIM, van Kraaij MGJ, Schipper P, Nijhuis M. Applicability of a real-time quantitative PCR assay for diagnosis of respiratory syncytial virus infection in immunocompromised adults. J Clin Microbiol. 2003;41(9):4378-81.

14. Freitas AR, Donalisio MR. Respiratory syncytial virus seasonality in Brazil: implications for the immunisation policy for at-risk populations. Mem Inst Oswaldo Cruz. 2016;111(5):294-301.

15. Durigon GS, Oliveira DB, Felicio MC, Finelli C, Pereira MF, Storni JG, Caldeira $\mathrm{RN}$, Berezin RC, Durigon EL, Berezin EN. Poor outcome of acute respiratory infection in young children with underlying health condition in Brazil. Int J Infect Dis. 2015;34:3-7.

16. Gurgel RQ, Bezerra PG, Duarte Mdo C, Moura AÁ, Souza EL, Silva LS, Suzuki CE, Peixoto RB. Relative frequency, possible risk factors, viral Codetection rates, and seasonality of respiratory syncytial virus among children with lower respiratory tract infection in northeastern Brazil. Medicine (Baltimore). 2016;95(15):e3090.

17. Monteiro Al, Bellei NC, Sousa AR, dos Santos AM, Weckx LY. Respiratory infections in children up to two years of age on prophylaxis with palivizumab. Rev Paul Pediatr. 2014;32(2):152-8.

18. Kim AY, Jung SY, Choi JY, Kim GB, Kim YH, Shim WS, et al. Retrospective multicenter study of respiratory syncytial virus prophylaxis in Korean children with congenital heart diseases. Korean Circ J. 2016;46(5):719-26.

19. Castillo LM, Bugarin G, Arias JC, Barajas Rangel Jl, Serra ME, Vain N. One-year observational study of palivizumab prophylaxis on infants at risk for respiratory syncytial virus infection in Latin America. J Pediatr. 2017;93(5):467-74.

20. Andres S, Bauer G, Rodrlguez S, Novali L, Micheli D, FariÒa D. Hospitalization due to respiratory syncytial virus infection in patients under 2 years of age with hemodynamically significant congenital heart disease. J Pediatr. 2012;88(3):246-52.

21. Pongiglione G, Possidoni A, di Luzio Paparatti U, Costanzo AM, Gualberti G, Bonvicini $\mathrm{M}$, et al. Incidence of respiratory disease during the first twotyears of life in children with hemodynamically significant congenital heart disease in Italy: a retrospective study. Pediatr Cardiol. 2016;37(8):1581-9.

\section{Publisher's Note}

Springer Nature remains neutral with regard to jurisdictional claims in published maps and institutional affiliations.

Ready to submit your research? Choose BMC and benefit from:

- fast, convenient online submission

- thorough peer review by experienced researchers in your field

- rapid publication on acceptance

- support for research data, including large and complex data types

- gold Open Access which fosters wider collaboration and increased citations

- maximum visibility for your research: over $100 \mathrm{M}$ website views per year

At BMC, research is always in progress.

Learn more biomedcentral.com/submission 